\title{
Coordination Chemistry: Niobium(V) and Tantalum(V) with O-Donor Ligands
}

Alebel Nibret Belay ${ }^{1}$, Johan A. Venter ${ }^{2}$, Andreas Roodt ${ }^{2}$

${ }^{1}$ Bahir Dar University Department Of Chemistry, Ethiopia And University Of The Fre, Bloemfontein, South Africa, ${ }^{2}$ Chemistry And University of the Free State, Bloemfontein, South Africa

E-mail: crossispower@gmail.com

The close chemical similarity of niobium(V) and tantalum(V), only slightly less studied than that of group (IV) and other transition metals, including its sensitivity to trace of moisture, and ease of oxidation causes it being difficult to handle and store. They also exhibit hard metal centres and display similar chemistry[1]. The study of this group 5 metals and their behaviour towards different ligands, which include mono- (halido and pseudo halido) and bidentate hard ligands with $\mathrm{O}, \mathrm{O}^{\prime}-$ and $\mathrm{N}, \mathrm{O}$-donor atoms are being investigated in our group[2]. Specific bidentate ligands included cupferrate, hopo, mpo, and $\mathrm{H} 2 \mathrm{CA}$ (where hopoH = 2-hydroxypyridine- $\mathrm{N}$-oxide, $\mathrm{mpoH}=2$-mercaptoypyridine- $\mathrm{N}$-oxide, dcbqH2 = 2,5-dichloro-3,6dihydroxy-1,4-benzoquinone and cupferron is $\mathrm{N}$-phenyl- $\mathrm{N}$-nitrosohydroxylamine) are good ligands for hard transition metal centres and form stable complexes. In this presentation, different synthetic procedures and characterization methods for these complexes will be discussed[3]. The compounds that were synthesised include [NbO(cupf)3], [Ta(hopo)4], [TaO(hopo)3], [Nb4O6Cl8(CA-2)2][Et4N]4, [NbOS(mpo)2(POPh3)] and cis-[NbO2(dcbqH2)2(POPh3)], which have been characterised by IR, NMR, UV/Vis and X-ray diffraction. All these mentioned ligands form a five-membered ring with a small bite angle when coordinated to the $\mathrm{M}(\mathrm{V})$ metal centre as compared with previously reported six-membered rings. Different structures and the comparative bonds and packing characteristics in the above, as well as other related compounds, will be discussed in this presentation(see Figure A and B).

[1] Herbst, L. Visser, H.G. and Roodt, A. (2014). Advanced Materials Research, 1019, 412-418.[2] Koen, R. Roodt, A. and Visser, H.G. (2014). Advanced Materials Research, 1019, 426-432.[3] Belay, A. N. Koen, R. Venter, J.A. and Drost, R.M. (2016). Zeitschrift fur Kristallographie: NCS, 231, 513-515

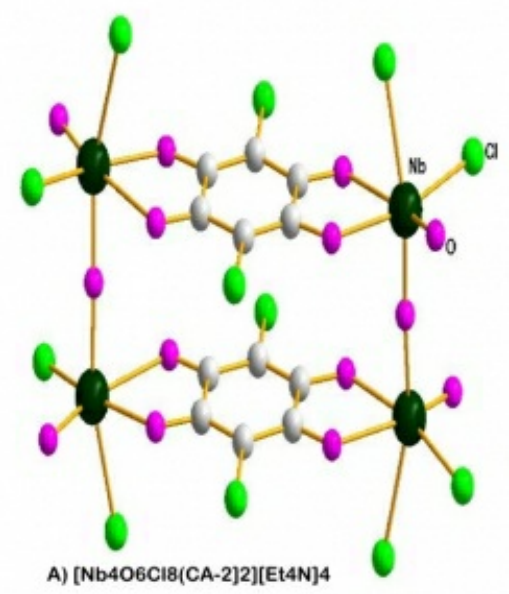

A) $[\mathrm{Nb} 4 \mathrm{O} 6 \mathrm{C} 18(\mathrm{CA}-2] 2][\mathrm{Et} 4 \mathrm{~N}) 4$

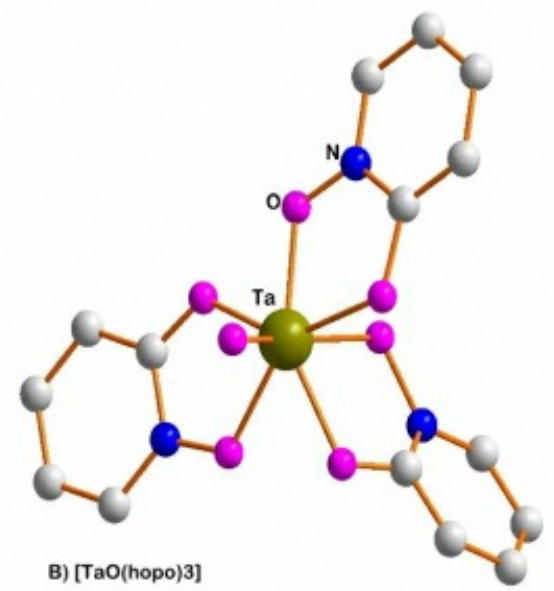

B) $[\mathrm{TaO}(\mathrm{hopo}) 3]$

Keywords: bidentate ligands, niobium, separation. 